\title{
Social Security Reform and Temptation
}

\author{
Cagri Seda Kumru \\ Athanasios C. Thanopoulos
}

CESIFo WORKING PAPER NO. 2778

CATEgory 1: Public FinANCE

SEPTEMBER 2009

Presented at CESifo Venice Summer Institute, July 2009

\footnotetext{
An electronic version of the paper may be downloaded

- from the SSRN website: wWw.SSRN.com

- from the RePEc website:

- from the CESifo website:

www.RePEc.org

www.CESifo-group.org/wp
} 


\title{
Social Security Reform and Temptation
}

\begin{abstract}
This paper analyzes a fully funded social security system under the assumption that agents face temptation issues. Agents are required to save through individually managed Personal Security Accounts without, and with mandatory annuitization. When the analysis is restricted to CRRA preferences our results are congruent with the literature indicating that the complete elimination of social security is the reform scenario that maximizes welfare improvement. However, when self control preferences are introduced, and as the intensity of self control becomes progressively more severe the "social security elimination" scenario loses ground very rapidly. In fact, in the case of very severe temptation the elimination of social security becomes the least desirable alternative. Under the light of the above findings, any reform proposal regarding the social security system should consider departures from standard preferences to preference specifications suitable for dealing with preference reversals.
\end{abstract}

JEL Code: E60, H55.

Keywords: funded social security, unfunded social security, self-control preferences.

\author{
Cagri Seda Kumru \\ University of New South Wales \\ School of Economics \\ Sydney, NSW, 2052 \\ Australia \\ cs.kumru@unsw.edu.au
}

\author{
Athanasios C. Thanopoulos \\ University of Pittsburgh \\ Department of Economics \\ Pittsburgh, PA, 15260 \\ USA \\ att8@pitt.edu
}

$27^{\text {th }}$ August 2009

We thank David N. DeJong, Daniele Coen-Pirani, John Duffy, Jack Ochs, John Piggott, and participants at the 2009 Midwest Macroeconomics Meetings and at the Behavioral Public Economics Workshop of the 10th CESIfo Venice Summer Institute for their comments. Cagri S. Kumru would like to thank the Australian Research Council for financial support. 


\section{Introduction}

There is an abundance of studies related to the importance of social security and its impact on welfare. The primary reason for this is its dramatically growing scale which triggers renewed academic debate regarding the optimal allocation of the available resources. This controversy stems from the huge monetary burden that the mere presence and administration of a social security system entails for the society and the associated budget implications: Old age, disability, unemployment and health insurance policies have evolved into the most expensive items on government budgets.

Most of the studies that seem to emerge as a direct or implicit offspring of this debate focus on the welfare implications of alternative social security schemes in an economy. In the very core of this debate one can clearly identify the dilemma between an "unfunded" (Pay-As-You-Go) versus a "funded" social security system. In an unfunded system, resources are transferred statically from the working population to the concurrent retirees (inter-generational transfers). In contrast, a funded system prescribes a dynamic allocation of resources within the same generation (inter-temporal within the same generation transfers). While both systems rely on an external institution (e.g. government) in order to be implemented, their different logic and mechanics eventually induce entirely different risk sharing properties as well as savings incentives. Therefore, their welfare implications may significantly differ because of this difference.

Population ageing as a result of the declining population growth rate and decreasing birth rate have challenged enormously the sustainability of a PAYG system and called for a minimization of the fiscal burden through tax reforms and benefits restructuring. As a result, there are numerous studies suggesting alternative institutional arrangements that could be more robust to adverse demographic shocks. However, as much as converting an unfunded system to a fully (or partially) funded one may seem a plausible solution, in most cases the transition costs associated with such a reform make it prohibitively costly [DeNardi et al. (1999)].

The welfare implications of social security are well identified in the relevant literature. ${ }^{1}$ Several studies [e.g. Storesletten et al. (1999)] comparing different social security systems typically compare welfare across alternative steady states, each corresponding to a stationary equilibrium with a different social security system. Focusing only on unfunded social security, Imrohoroglu et al. (1995) emphasize the detrimental effects that such an arrangement has to the overall welfare in a country.

However, all the above studies ignore alternative preference specifications that may

\footnotetext{
${ }^{1}$ The interest in the welfare implications of a social security system has been sparked with the seminal work of Diamond (1965). The first quantitative model that assessed the welfare implications of the system was created by Auerbach \& Kotlikoff (1987).
} 
be binding in several cases: Imrohoroglu et al. (2003) and Fehr et al. (2008) use timeinconsistent preferences while Kumru \& Thanopoulos (2008) use self-control preferences to highlight that in a context of unfunded social security welfare may be critically affected by the preference specification. In a recent paper, Fehr \& Kindermann (2009) study the implications of individual retirement accounts (IRA) on economic aggregates and welfare in the context of a general equilibrium model populated by either rational individuals or individuals with time-inconsistent preferences. Furthermore, the experimental economics literature documents some evidence that preferences show some degree of time inconsistency and agents suffer from temptation, a fact that further supports the results in the aforementioned studies. ${ }^{2}$

In this study, we would like to quantitatively assess the welfare implications of the reform of the current unfunded social security system into a partially funded or fully privatized one, under the assumption that individuals face self-control problems. We proceed by assessing in terms of welfare a hybrid (partially funded) social security system under the alternative hypotheses of self-control or CRRA preferences. The apparatus by means of which we model departures from unfunded social security is a Personal Security Account (PSA). Within that class of "funded" models, we investigate two competing scenarios involving PSAs: one without mandatory annuitization and an alternative one that prescribes a mandatory annuitization of retirement benefits.

Moreover, in order to capture our agents' temptation towards current consumption, our model economies make use of the preference structure pioneered by Phelps \& Pollak (1968) and further elaborated by Gul \& Pesendorfer (2004) to model self-control issues. Gul \& Pesendorfer (2004) identified a particular class of utility functions that provide a time-consistent model suitable for addressing the preference reversals that motivated the time inconsistency literature. The key theme here is that self-control preferences assume that agents maximize a utility function that is a 'compromise' between the standard utility (or 'commitment' utility) and a 'temptation' utility. The conflicting ways by which agents derive utility in this setting, is the device through which the trade-off between the temptation to consume on the one hand, and the long-run self interest of the agent on the other is captured. The main benefit is that self-control preferences remain perfectly time-consistent and, contrary to time-inconsistent preferences, allow agents in our model to commit.

With the exception of the aforementioned difference in the specification of preferences, our model specification follows that of Imrohoroglu et al. (2003) and Fuster et al. (2005). Furthermore, our economic environment features uninsurable individual income shocks, borrowing constraints and missing annuity markets.

\footnotetext{
${ }^{2}$ For a recent overview of studies that provide evidence that individuals indeed exhibit bias toward immediate gratification see Frederick et al. (2002).
} 
We aim to contribute to the debate on the reform of social security. Our augmented model allows us to look at the welfare gains or losses due to the reforms from a different angle. In particular, it allows us to assess the welfare-enhancing potential of mandatory savings versus mandatory annuitization of accumulated PSA wealth at retirement. For the sake of comparability of our results, the particular specification of those alternative policies is purposely chosen to match the proposals analyzed in the literature (Storesletten et al. (1999) and Fuster et al. (2005)), as well as those featuring in the reform recommendations made by the 1997 Advisory Council on Social Security.

Moreover, changing the preference structure is very important for theoretical purposes because it enhances our understanding of the mechanics of similar models in the literature by providing an additional channel through which capital accumulation is distorted. Equally importantly, an augmented preference structure is also essential for providing a comprehensive comparison framework for policy makers in their evaluation of various proposals. As shown in Imrohoroglu et al. (2003) and Kumru \& Thanopoulos (2008) the presence of slightly far-sighted or current consumption favored agents changes substantially the welfare implications of the system.

Our results in this paper highlight the important role that self control preferences play, especially with regards to the kind of reform that could generate the highest welfare. While if we restrict our analysis to CRRA preferences our findings initially confirm those in other studies (e.g.,Fuster et al. (2005)), i.e., we also find that the complete elimination of social security is the policy that maximizes welfare, we come across a drastic alteration of this outcome when self-control preferences are introduced: the elimination of social security is the least desirable policy reform from the point of view of welfare. That is, the presence of self-control preferences renders the elimination scenario the least appealing one compared to the examined alternatives.

Along the same lines, our research indicates that the clear-cut advantage of the elimination scenario under CRRA preferences fades away as self control becomes gradually more severe. Our robustness tests confirm this finding: in the case of severe temptation the CRRA pecking order is completely reversed, and the elimination of social security becomes the least desirable scenario.

Under the light of the above findings, any reform proposal regarding the social security system should consider departures from standard preferences to preference specifications suitable for dealing with preference reversals. 


\section{$2 \quad$ A Model of Social Security}

The model we consider in this section is quite standard in the social security literature. In particular, our model follows that of Imrohoroglu et al. (2003).

\subsection{The Environment}

We consider a stationary overlapping generations economy in discrete time. Each period a new generation is born which is modeled to be $n$ percent larger than the previous generation. Agents face lives of uncertain duration and some live through the maximum possible life span, denoted by $J$. At any given time $j$ within their life-span, all agents have a (time-invariant) conditional probability $s_{j} \in(0,1)$ of surviving from age $j-1$ to $j$, conditional on having survived up to age $j-1$. Our stationary population assumption implies that age $j$ agents constitute a fraction $\mu_{j}$ of the population at any given date. The cohort shares $\left\{\mu_{j}\right\}_{j=1}^{J}$ are given by

$$
\mu_{j+1}=\frac{\mu_{j} s_{j+1}}{1+n}
$$

while their sum is normalized to 1.

\subsection{Preferences}

Agents in our economy feature self-control preferences. That is, their preferences are such that in every period they induce a temptation to consume their entire wealth. Resisting temptation gives rise to a self-control cost; note that the latter feature is absent in models with CRRA and quasi-hyperbolic preferences. We follow Gul \& Pesendorfer (2004) and DeJong \& Ripoll (2007) and proceed to model self-control preferences recursively.

Let $W(x)$ denote the maximized value of the expected discounted objective function with state $x$. The utility function of an agent is as follows:

$$
W(x)=\max _{c}\left\{u(c)+v(c)+\beta E W\left(x^{\prime}\right)\right\}-\max _{\check{c}} v(\check{c})
$$

where $E$ is the expectation operator; $u($.$) and v($.$) are von Neumann-Morgenstern utility$ functions; $0<\beta<1$ is a discount factor; $c$ represents the "commitment" consumption; $\check{c}$ is the "temptation" consumption; and $x^{\prime}$ denotes next period state variable. As in the section above, $u($.$) represents the momentary utility function and v($.$) represents tempta-$ tion. In particular, $v(c)-\max _{\check{c}} v(\check{c})$ denotes the disutility from choosing consumption $c$ instead of $\check{c}$. The concavity or convexity of $v($.$) turns out to be very important for our$ 
analysis. $^{3}$

The momentary utility, convex temptation and concave temptation functions are assumed to take the following forms respectively:

$$
\begin{gathered}
u(c)=\frac{c^{1-\gamma}-1}{1-\gamma} \\
v(c)=\lambda \frac{c^{\rho}}{\rho} \\
v(c)=\lambda u(c)
\end{gathered}
$$

In the specification above, higher values of the scale parameter $\lambda>0$, imply an increase in the share of "temptation" utility, i.e. a higher $\lambda$ increases the importance of current consumption for an agent. The momentary utility function $u($.$) is a standard$ Constant Relative Risk Aversion (CRRA) form, $\gamma>0$ measures the degree of relative risk aversion (and $1 / \gamma$ the inter-temporal elasticity of substitution).

\subsection{Production Function}

Firms have access to a constant returns-to-scale Cobb-Douglas technology that produces output $\left(Y_{t}\right)$ by using labor input $\left(L_{t}=0.94 \sum_{j=1}^{j^{*}-1} \mu_{j} \epsilon_{j}\right),{ }^{4}$ and capital input $\left(K_{t}\right)$ which is rented from households:

$$
Y_{t}=F\left(K_{t}, L_{t}\right)=A_{t} K_{t}^{\alpha} L_{t}^{(1-\alpha)}
$$

where $A_{t}$ represents the state of technology; $\alpha \in(0,1)$ is the capital's share of output. Defining the capital-labor ratio as $\frac{K_{t}}{L_{t}}$, we can write the production function in the intensive form as follows:

$$
y_{t}=f\left(k_{t}\right)=A_{t} k_{t}^{\alpha}
$$

The technology parameter $A_{t}$ grows at a constant rate $g$ and capital depreciates at a constant rate $\delta$. Competitive firms in this economy maximize their profits by setting the real rate of return from asset holdings $r$ and the real wage rate $w$ according to the following:

$$
r_{t}=A_{t} \alpha k_{t}^{\alpha-1}-\delta
$$

\footnotetext{
${ }^{3}$ Notice that if $v($.$) is convex, we need to make sure that v()+.u($.$) is stricly concave. In particular,$ $\gamma>0, \rho>1$ and $0<\lambda<\gamma /\left(c^{\gamma+1} c^{\rho-2}\right)$ guarantee that $u($.$) is concave, v($.$) is convex and u()+.v($.$) is$ strictly concave. When $v($.$) is concave, one should show that W($.$) is strictly concave.$

${ }^{4} j^{*}$ denotes the compulsory retirement age and $\epsilon_{j}$ denotes the efficiency index of an age $j$ agent.
} 


$$
w_{t}=A_{t}(1-\alpha) k_{t}^{\alpha}
$$

Since we are concerned only with the behavior of steady-state equilibria, we will henceforth drop the time subscript for the rest of the analysis.

\subsection{Budget Constraints}

The exogenously given mandatory retirement age is $j^{*}$. Agents who are younger than age $j^{*}$ face a stochastic employment opportunity at each period $j<j^{*}$. Individuals who find an employment opportunity, supply inelastically one unit of labor. ${ }^{5}$ We denote the employment state variable by $e \in\{0,1\}$ where 0 and 1 denote unemployment and employment states respectively. Furthermore, we postulate that the employment state follows a first-order Markov process. The transition probability distribution between the current employment state $e$ and next period's employment state $e^{\prime}$ is represented by the $2 \times 2$ matrix $\Pi\left(e^{\prime}, e\right)=\left[\pi_{k^{\prime} k}\right]$ where $k^{\prime}, k=0,1$ and $\pi_{k^{\prime} k}=\operatorname{Pr}\left\{e^{\prime}=k^{\prime} \mid e=k\right\}$.

An employed $(e=1)$ agent earns $w \epsilon_{j}$ where $w$ denotes the wage rate per efficiency unit of labor in terms of the consumption good and $\epsilon_{j}$ denotes the efficiency index of an age $j$ agent. If, on the other hand, an agent is unemployed $(e=0)$, he receives an unemployment insurance benefit equal to a fraction $\phi$ of the wage of an employed agent, resulting in the amount $\phi w \epsilon_{j} ; \phi$ is the unemployment insurance replacement ratio.

The disposable (after-tax) income of an agent at age $j$ can be written as

$$
q_{t}= \begin{cases}\left(1-\tau_{s}-\tau_{u}\right) w \epsilon_{j} & \text { for } j=1,2, \ldots, j^{*}-1, \text { if } e=1 \\ \phi w \epsilon_{j} & \text { for } j=1,2, \ldots, j^{*}-1, \text { if } e=0 \\ b_{j} & \text { for } j=j^{*}, j^{*}+1, \ldots, J\end{cases}
$$

where $\tau_{s}$ and $\tau_{u}$ represent the social security payroll tax rate and the unemployment insurance tax rate respectively. ${ }^{6}$

We assume away any private insurance markets against unemployment risk and private annuities' markets against the risk of outliving one's own resources ${ }^{7}$. The only available device to smooth consumption across one's lifetime is the accumulation of assets

\footnotetext{
${ }^{5}$ Adding labor-leisure choice into the model requires the modification of preferences in a way that agents are not only tempted by current consumption but also by current leisure.

${ }^{6}$ Note that in the US social security system both retirement and unemployment benefits are taxed (Diamond \& Orszag (2005)). For the sake of less cumbersome notation we refrain from incorporating those taxes in our analysis.

${ }^{7}$ Although a market for private annuities exists in the U.S. it is nevertheless very thin (Feldstein \& Liebman (2002), Imrohoroglu et al. (1995)). Hence, our assumption seems innocuous. In our model, social security partially fulfills the role of the missing annuities' market (it can be considered as mandatory annutization). Diamond et al. (2005) analyze thoroughly the relationship between annuities and individual welfare. He shows that full annuitization of wealth is optimal under certain conditions.
} 
in terms of physical capital. Agents cannot hold negative assets at any period. ${ }^{8}$ Since death is certain at $J$ and there is no bequest motive, the borrowing constraint can be stated as: ${ }^{9}$

$$
\left\{\begin{array}{cc}
a_{j} \geq 0 & \text { for } j=1, \ldots J-1 \\
a_{j}=0 & \text { for } j=J
\end{array}\right.
$$

We can now proceed to write the growth-adjusted budget constraint of an agent as follows

$$
\begin{aligned}
& (1+g) a_{j}+\kappa w \epsilon_{j}+c_{t}=(1+r) a_{j-1}+q_{j}+\eta \\
& (1+g) a_{j}+\kappa w \epsilon_{j}+\check{c}_{j}=(1+r) a_{j-1}+q_{j}+\eta
\end{aligned}
$$

where $r$ is the rate of return from asset holdings and $\eta$ denotes the amount of accidental bequests, to be distributed equally to all alive members of the society. The compulsory contribution/deposit rate for personal security accounts (PSA) $\kappa$ is greater than zero for employed individuals if PSAs exist in the economy, otherwise, $\kappa=0$. The details for the law of motion of the PSAs are given in the next section.

\subsection{Social Security and Fiscal Policy}

We consider three distinct social security arrangements: Pay-As-You-Go, Personal Security Accounts without annuitization, and Personal Security Accounts with mandatory annuitization. We follow Fuster et al. (2005) as far as our modelling of Personal Security Accounts is concerned.

\subsubsection{PAYG}

A PAYG system in our model economy resembles to that of the US Economy. Agents retire at age $j^{*}$ and receive social security benefit $b$. The social security benefit $b$ is defined

\footnotetext{
${ }^{8}$ In other words, an agent faces a borrowing (or liquidity) constraint. Given the size of private credit markets, this assumption may not seem so innocuous. There are two main reasons behind this assumption: First, we would like to engage in a careful comparison of our results with those of the existing social security literature where this assumption is a standard one. Second, the fact that agents are not allowed to borrow against their future income induces an additional boost in (private) savings for precautionary purposes, since they may become/remain unemployed with a positive probability. It would be a fair question to explore the consequences of alleviating this constraint in our environment and allow borrowing against future income. In that case however, the ability to borrow would lower agents' marginal propensity to save (for precautionary reasons), thus implying that the effects of selfcontrol and ability to borrow against future income are highly correlated; consequently, the effect of social security on savings due to self-control will be non-identifiable. In a recent paper, Rojas \& Urrutia (2008) show that adding an endogenous borrowing constraint reduces the welfare cost of having a social security.

${ }^{9}$ Allowing a bequest motive does change the welfare implications of a social security system. Fuster et al. (2003) make a welfare analysis of social security in a dynastic framework and show that steady state welfare increases with social security.
} 
as a fraction $\theta$ of an average life-time employed income, which is, notably, independent of a particular agent's employment history.

$$
b=\theta \frac{\sum_{j=1}^{j^{*}-1} w \epsilon_{j}}{j^{*}-1} \text { for } j=j^{*}, j^{*}+1, \ldots, J .
$$

While technology grows at rate $g$, the pension payments remain constant during retirement. Therefore, the growth-adjusted pension payments are given as follows:

$$
b_{j}=\frac{b}{(1+g)^{j-j^{*}}} \text { for } j=j^{*}, j^{*}+1, \ldots, J .
$$

The social security system is self-financing and the government administers the program. We restrict our attention to social security arrangements that are described by the pair $\left(\theta, \tau_{s}\right)$. The self-financing conditions are as follows:

$$
\tau_{s} \sum_{j=1}^{j^{*}-1} \sum_{a} \mu_{j} \Lambda_{j}(a, e=1) w \epsilon_{j}=\sum_{j=j^{*}}^{J} \sum_{a} \mu_{j} \Lambda_{j}(a, e) b_{j},
$$

where $\Lambda_{j}(a, e)$ is the set of age dependent, time invariant measures of individuals.

If agents in this economy die before age $J$, their remaining assets will be distributed evenly to all of the survivors in a lump-sum fashion as follows:

$$
\eta=\sum_{j} \sum_{a} \sum_{e} \mu_{j} \Lambda_{j}(a, e)\left(1-s_{j+1}\right) a_{j}(a, e)
$$

\subsubsection{Personal Security Accounts (PSA) without Annuitization}

In this section, we consider a two-tier social security system. The first tier is a PAYGfinanced universal flat pension benefit. The amount of benefit is set as $10 \%$ of the per capita gross domestic product (GDP). As in the above benchmark case, the first tier is self-financing and administered by the government.

$$
\tau_{s} \sum_{j=1}^{j^{*}-1} \sum_{a} \mu_{j} \Lambda_{j}(a, e=1) w \epsilon_{j}=\sum_{j=j^{*}}^{J} \sum_{a} \mu_{j} \Lambda_{j}(a, e) b^{*}
$$

where $b^{*}=0.10 y$ and $y=w /(1-\alpha)$.

Hence, the equilibrium tax rate can be found by using the equation below:

$$
\tau_{s}=\frac{0.10}{1-\alpha} \frac{\sum_{j=j^{*}}^{J} \sum_{a} \mu_{j} \Lambda_{j}(a, e)}{\sum_{j=1}^{j^{*}-1} \sum_{a} \mu_{j} \Lambda_{j}(a, e=1) \epsilon_{j}}
$$


The second tier of retirement benefits is financed through mandatory savings. In this setting, employed individuals are required to deposit $2.7 \%$ of their earnings into their privately managed personal savings account. The funds on PSA earn the tax-free rate of return on capital and they cannot be withdrawn until the mandatory retirement age. Individuals' second-tier benefits depend on the funds accumulated in their PSAs. The law of motion for the PSA is the following:

$$
\begin{aligned}
(1+g) \varkappa_{j+1} & =(1+r) \varkappa_{j}+\kappa w \epsilon_{j}, \\
\varkappa_{1} & =0
\end{aligned}
$$

where $\kappa=0.027$ is the required deposit rate and $\varkappa_{j+1}$ denotes an age $j+1$ individual's accumulated PSA funds. Individuals receive a lump-sum transfer of funds accumulated in their PSAs when they are retired at age $j^{*}$. Hence, retirement benefits can be written as follows:

$$
b_{j}=\left\{\begin{array}{c}
b^{*}+(1+r) \varkappa_{j^{*}}, \text { for } j=j^{*} \\
\frac{b^{*}}{(1+g)^{j-j^{*}}}, \text { otherwise }
\end{array}\right.
$$

If an individual dies before one's retirement, the accumulated funds in his PSA account are distributed to the remaining members of the society in a lump-sum fashion along with their assets:

$$
\eta=\sum_{j} \sum_{a} \sum_{e} \mu_{j} \Lambda_{j}(a, e)\left(1-s_{j+1}\right)\left[a_{j}(a, e)+\varkappa_{j}(e)\right]
$$

\subsubsection{Personal Security Accounts with Mandatory Annuitization (PSA+Annuity)}

We consider a two-tier pension system here as well. While the first tier is exactly the same as that of the previous section, the second tier differs. The government annuitizes funds accumulated in individuals' PSAs and hence, individuals receive annuity payments equal to $b^{\prime}=p(1+r) \varkappa_{j^{*}}$, where $p$ denotes the proportion, i.e., the amount of an annuity payment received by an individual, which is obviously proportional to the accumulated funds in his PSA account, and is determined endogenously.

The government sets the proportion $p$ in such a way that the expected present value of the aggregate annuity payments of the generation that retires now $(\bar{E})$ is equal to the funds held in PSAs, including the funds of individuals from the same generation who died before their retirement. The expected present value of the aggregate annuity payments of the generation that retires now is equal to the following: 


$$
\bar{E}=p(1+r) \varkappa_{j^{*}} \sum_{j=j^{*}}^{J}(1+r)^{j^{*}-j} \prod_{i=1}^{j-1} \mu_{i} .
$$

The aggregate funds of the individuals from the same generation who survived to retirement and who died before their retirement are given as

$$
(1+r) \varkappa_{j^{*}} \prod_{i=1}^{j^{*}-1} \mu_{i}
$$

and

$$
(1+r) \sum_{j=2}^{j^{*}}\left(\frac{1+r}{1+g}\right)^{j^{*}-j} \varkappa_{j}\left(1-\mu_{j-1}\right) \prod_{i=1}^{j-2} \mu_{i}
$$

respectively. Hence, the proportion $p$ can be written as follows:

$$
p=\frac{(1+r) \varkappa_{j^{*}} \prod_{i=1}^{j^{*}-1} \mu_{i}+(1+r) \sum_{j=2}^{j^{*}}\left(\frac{1+r}{1+g}\right)^{j^{*}-j} \varkappa_{j}\left(1-\mu_{j-1}\right) \prod_{i=1}^{j-2} \mu_{i}}{(1+r) \varkappa_{j^{*}} \sum_{j=j^{*}}^{J}(1+r)^{j^{*}-j} \prod_{i=1}^{j-1} \mu_{i}}
$$

Because individuals' survival rates do not depend on their types in our model economy, the above return is actuarially fair, it could be offered by private firms and there is no need for government intervention. Yet, in our model, the private annuity market is closed by assumption and hence the government has to administer it. If individuals' survival rates were type-dependent, the above equation would yield an actuarially not fair premium. This, in turn, would call for government intervention because adverse selection issues would cause a market breakdown.

The law of motion of the funds aggregated in PSA by the government is the following:

$$
(1+n)(1+g) \digamma_{t+1}=(1+r) \digamma_{t}+\kappa w L-B^{\prime}
$$

where $\kappa=0.027$ is the social security tax rate, $L=0.94 \sum_{j=1}^{j^{*}-1} \mu_{j} \epsilon_{j}$ is the aggregate labor supply, and $B^{\prime}=\sum_{j=j^{*}}^{J} b^{\prime}(1+g)^{j^{*}-j} \mu_{j}$ is the aggregate annuity payment at time $t$.

Hence, the expression for retirement benefits featuring PSAs under a mandatory annuitization scheme can be written as follows: 


$$
b_{j}=\frac{b^{*}+b^{\prime}}{(1+g)^{j-j^{*}}} \text { for } j=j^{*}, \ldots, J .
$$

In addition to a social security program, the government also runs a self-financing unemployment program. The self-financing condition for the unemployment insurance program is as follows:

$$
\tau_{u} \sum_{j=1}^{j^{*}-1} \sum_{a} \mu_{j} \Lambda_{j}(a, e=1) w \epsilon_{j}=\sum_{j=1}^{j^{*}-1} \sum_{a} \mu_{j} \Lambda_{j}(a, e=0) \phi w \epsilon_{j}
$$

where $\phi$ is the unemployment insurance replacement rate.

\subsection{An Agent's Dynamic Program}

We assume that the temptation function $v($.$) is strictly increasing, i.e., an agent is temp-$ ted to consume his entire wealth in each period. This implies that the agent maximizes the second part of equation (1) by holding zero assets for the next period, i.e., setting $a_{j}=0$ in equation (9). In this economy, the agent's state vector $x$ contains the current asset holdings and the employment state. Hence, we can write the agent's dynamic program for any arbitrary two periods as follows:

$$
W(x)=\max _{c}\left\{u(c)+v(c)+\beta E_{s^{\prime}} W\left(x^{\prime}\right)\right\}-v((1+r) a+q+\eta)
$$

subject to

$$
a^{\prime}+c=(1+r) a+q+\eta, a^{\prime} \geq 0, a_{0} \text { is given. }
$$

where $E_{s^{\prime}}$ denotes the expectation over survival probabilities.

If the agent succumbs to a temptation and consumes his entire wealth, the term $v(c)-v((1+r) a+q+\eta)$ in the equation above cancels out. When he resists to temptation and consumes less than his wealth, he faces a self-control cost at the amount of $v(c)-$ $v((1+r) a+q+\eta)$. The agent tries to balance his urge for utility from current consumption $v(c)$ and long-term commitment utility $u(c)+\beta E_{s^{\prime}} W\left(x^{\prime}\right)$.

\subsection{Steady State Equilibrium}

In our characterization of the steady-state equilibrium, we follow Imrohoroglu et al. (2003) and Hugget \& Ventura (1999).

Given a set of government policy $\left\{\theta, \phi, \tau_{s}, \tau_{u}, \kappa\right\}$, a steady-state recursive competitive 
equilibrium is a set of value functions $\left\{W_{j}(x)\right\}_{j=1}^{J}$, household policy rules $\left\{a_{j}(x)\right\}_{j=1}^{J}$, time-invariant measures of agents $\left\{\Lambda_{j}(x)\right\}_{j=1}^{J}$, wage and interest rate $(w, r)$, and a lumpsum distribution of accidental bequests $\eta$ such that all of them satisfy the following:

- Factor prices $(w, r)$ that are derived from the firm's first-order conditions satisfy the equations (6) and (7).

- Given the government policy set $\left\{\theta, \phi, \tau_{s}, \tau_{u}, \kappa\right\}$, the factor prices $(w, r)$, and the lump-sum transfer of accidental bequests $\eta$, an agent's policy rule $\left\{a_{j}(x)\right\}_{j=1}^{J}$ solves the agent's maximization problem (16) subject to the budget constraint (17).

- Aggregation holds,

$$
K=\sum_{j} \sum_{a} \sum_{e} \mu_{j} \Lambda_{j}(x)\left[a_{j-1}(x)+\varkappa_{j}\right]
$$

- The set of age-dependent, time-invariant measures of agents satisfies in every period $t$

$$
\Lambda_{j}\left(x^{\prime}\right)=\sum_{e} \sum_{a} \Pi\left(e^{\prime}, e\right) \Lambda_{t-1}(x)
$$

where $\Lambda_{1}$ is given.

- The lump-sum distribution of accidental bequests $\eta$ satisfies the equation (11) if the PAYG or $P S A+A n n u i t y$ programs are in use, or else it satisfies the equation (13) if the $P S A$ program is in use.

- Both the social security system and the unemployment insurance benefit program are self-financing.

- The market clears

$$
\begin{aligned}
& \sum_{j} \sum_{a} \sum_{e} \mu_{j} \Lambda_{j}(x)\left[a_{j}(x)+\varkappa_{j}(x)+c_{j}(x)\right] \\
= & Y+(1-\delta) \sum_{j} \sum_{a} \sum_{e} \mu_{j} \Lambda_{j}(x)\left[a_{j-1}(x)+\varkappa_{j-1}(x)\right]
\end{aligned}
$$

\section{Calibration}

In this section, we briefly define the parameter values of our model. Each period in our model corresponds to a calendar year. 


\subsection{Demographic and Labor Market Parameters}

Agents are born at a real life age of 21(model age of 1) and they can live up to a maximum real life age of 85 (model age of 65 ). The population growth rate $n$ is assumed to be equal to the average U.S. population growth rate between 1931-2003 which corresponds, on average, to $1.19 \%$ per year ${ }^{10}$. The sequence of conditional survival probabilities is the same as the Social Security Administration's sequence of survival probabilities for men in the year 2001. The mandatory retirement age is equal to 65 (model age 45). In order to set the efficiency index, we choose the average of Hansen (1993)'s estimation of median wage rates for males and females for each age group. We interpolate the data by using the Spline Method and normalize the interpolated data to average unity. The employment transition probabilities are chosen to be compatible with the average unemployment rate in the U.S. which is approximately equal to 0.06 between 1948 and 2003. ${ }^{11}$ The implied employment transition matrix assumes the following form:

$$
\Pi\left(e, e^{\prime}\right)=\left[\begin{array}{ll}
0.94 & 0.06 \\
0.94 & 0.06
\end{array}\right] .
$$

\subsection{Preference Parameters}

We choose the values of preference parameters $\rho, \gamma, \lambda$ and $\beta$ in such a way that our model economy's capital-output ratio matches that of the U.S. economy.

In the case where the temptation function $v($.$) is convex, we choose to follow Imro-$ horoglu et al. (2003) and DeJong \& Ripoll (2007), in letting $\gamma$ be centered at 2 with a standard deviation 1, i.e., $\gamma=2_{(1)}$. In our benchmark calibration, we initially set $\gamma=2$, and then check the robustness of our results by letting $\gamma=3$. Holding $\gamma$ constant, we choose different values of $\rho$ a priori, and calculate the corresponding $\lambda$ in such a way that $u()+.v($.$) stays a strictly concave function. For every triple \rho, \gamma$ and $\lambda$, we search over the values of $\beta$ that deliver the capital-output ratio which is compatible with its empirical counterpart. We assume that the social security replacement ratio is $50 \%$ and the unemployment replacement ratio is $25 \%$ during our search.

When the temptation function is concave, we follow DeJong \& Ripoll (2007) and set $\lambda=0.0786_{(0.056)}$

\footnotetext{
${ }^{10}$ The population data are obtained from the U. S. Census Bureau (U.S. Census Bureau (2006)) .

${ }^{11}$ The unemployment data are taken from the U. S. Department of Labor (US Department of Labor (2006)).
} 


\subsection{Production Parameters}

The parameters describing the production side of the economy are chosen to match the long-run features of the U.S. economy. Following Imrohoroglu et al. (2003)), we set the capital share of output $\alpha$ equal to 0.310 and the annual depreciation rate of physical capital equal to 0.069 . The rate of technological progress $g$ is assumed to be equal to $2.1 \%$, which is the actual average growth rate of GDP per capita taken over the time interval from 1959 to 1994 (Hugget \& Ventura (1999)). The technology parameter A, can be chosen freely. In our calibration exercises, it is set equal to 1.01. All per capita quantities are assumed to grow at a constant rate $g$.

\subsection{Government}

We set the unemployment insurance replacement ratio $(\phi)$ equal to $25 \%$ of the employed wage. In the benchmark case, we set the social security replacement ratio $(\theta)$ equal to $50 \%$. Alternatively, we can choose the payroll tax rate $\left(\tau_{s}\right)$ and the unemployment insurance tax rate $\left(\tau_{u}\right)$ instead of the replacement ratios. Since the social security and the unemployment insurance benefits are self-financing, calibrating the replacement ratios will automatically pin-down the tax rates. This holds true because agents inelastically supply one unit of labor whenever they find an opportunity to work, and changes in tax rates do not affect their supply of labor. ${ }^{12}$ In the PSA cases, the first tier universal benefits are set equal to $10 \%$ of per capita GDP and the social security tax rate for second tier benefits $\kappa$ is set equal to $2.7 \%$.

\subsection{Solution Method}

We use discrete-time, discrete-state optimization techniques to find a steady-state equilibrium of our hypothetical economy by using the aforementioned parameter values. Our solution method designedly resembles those of previous studies. ${ }^{13}$

A discrete set of asset values (containing 4097 points) is created. The lower bound and upper bound of the set are chosen in such a way that the set never binds. ${ }^{14}$ While the state space for working age agents comprises $4097 \times 2$ points, the state space for retired agents consists of only $4097 \times 1$ points (since there is no state transition after $\left.j^{*}\right)$.The discrete set of the control variable (consumption) contains $4097 \times 1$ points. We start with a guess about the aggregate capital stock and the level of accidental bequests

\footnotetext{
${ }^{12}$ However, if we calibrate a model featuring labor-leisure choice, tax rates should be used instead of replacement rates.

${ }^{13}$ See Imrohoroglu et al. (1995 and 2003) and Hugget and Ventura(1999).

${ }^{14} \mathrm{In}$ particular, the lower bound is equal to 0 and the upper bound is equal to 60 times greater than the annual income of an employed agent.
} 
and then solve agents' dynamic program by backward recursion. The time-invariant, age-dependent distribution of agents is obtained by forward recursion. After each loop, we calculate the new values for the accidental bequests and the capital stock. If the difference between the initial values and the new values exceed the tolerance value, we start a new loop with the new values. This procedure continues until we find values for the accidental bequests and the capital stock that are sufficiently close to their beginningof-loop values.

Table 1: Parameter Values of The Benchmark Calibration

\begin{tabular}{|c|c|}
\hline \multicolumn{2}{|l|}{ Demographics } \\
\hline Maximum possible life span $T$ & 65 \\
\hline Obligatory retirement age $t^{*}$ & 45 \\
\hline Growth rate of population $n$ & $1.19 \%$ \\
\hline Conditional survival probabilities $\left\{s_{t}\right\}_{t=1}^{T}$ & U.S. 2001 \\
\hline $\begin{aligned} \text { Labor efficiency profile }\left\{\epsilon_{j}\right\}_{t=1}^{t^{*}-1} \\
\text { Production }\end{aligned}$ & Hansen (1993) \\
\hline Capital share of GDP $\alpha$ & 0.310 \\
\hline Annual depreciation of capital stock $\delta$ & 0.069 \\
\hline Annual per capita output growth rate $g$ & $2.1 \%$ \\
\hline Markov Process for employment transition $\Pi$ & {$\left[\begin{array}{ll}0.94 & 0.06 \\
0.94 & 0.06\end{array}\right]$} \\
\hline \multicolumn{2}{|l|}{ Preferences } \\
\hline Annual discount factor of utility $\beta$ & 0.998 \\
\hline Scale factor of the temptation utility $\lambda$ & 0.000375 \\
\hline Risk aversion parameter $\gamma$ & 2.0 \\
\hline Risk loving parameter $\rho$ & 2.0 \\
\hline \multicolumn{2}{|l|}{ Government } \\
\hline Unemployment insurance replacement ratio $\phi$ & 0.25 \\
\hline Social security replacement ratio $\theta$ & {$[0,1]$} \\
\hline Compulsory deposit rate $\kappa$ & 0.027 \\
\hline
\end{tabular}

\section{Results}

In this section we first calibrate our model economy to the US data under the assumption that individuals have CRRA preferences and a PAYG system that is similar to that of the US is in use. We choose the social security replacement rate as $40 \%$ since it corresponds to the current average social security replacement rate in the US. Our aim is to gradually converge to the long term average of the US capital-output ratio of 2.5. Subsequently, we proceed to look at the implications of three reform proposals: 
The first reform proposal postulates the substitution of the current social security system by a two-tier scheme: a universal PAYG-financed basic pension combined with a Personal Security Account that does not require mandatory annuitization of benefits at retirement.

The second reform proposal is similar to the first one except that it prescribes a mandatory annuitization of the funds accumulated in PSA accounts.

Finally, the third reform proposal suggests the complete removal of the social security system; in terms of our model, this amounts to postulating that the social security replacement ratio is equal to zero.

The effects that the three competing scenarios have on economic aggregates, as well as their welfare implications are given in Table 2 . The welfare implications of a given policy are measured in terms of the average expected utility $(E U)$. The average expected utility of a policy is given in the last column of Table 2. Both our first reform proposal (featuring as "PSA" in Table 2) and our second one (featuring as "PSA+Annuity" in Table 2) prescribe a specific (given) rate of mandatory savings. We assume that the mandatory savings rate, denoted by $\kappa$, is equal to $2.7 \%$ of the gross individual labor income. As a consequence, individuals' payments to the social security system across $P A Y G, P S A$, and $P S A+$ Annuity policies are all equalized. It is a well established result in the literature that funded or partially funded social security systems induce an increase in capital accumulation as well as in other aggregate variables such as consumption and output (e.g. Storesletten et al. (1999)). However, the exact magnitudes of increase of those aggregate variables are sensitively dependent to the features of the model. Fuster et al. (2005) demonstrate that the increases in the absolute levels of aggregate variables are more moderate in an economy populated by altruistic individuals compared to an economy without altruistic individuals. Previous studies (Imrohoroglu et al. (1995), Imrohoroglu et al. (2003), and Hugget \& Ventura (1999)) also demonstrated that decreasing the social security replacement rate improves the social welfare whenever individuals have CRRA preferences. Their key finding was that the complete elimination of a PAYG system would deliver the highest social welfare.

In all tables, the values of the levels of economic aggregates as well as the average expected utility are normalized to 100 under a $P A Y G$ system. The values of the various reform proposals are calculated accordingly. Our results in Table 2 are consistent with those of previous studies mentioned above. Since both PSA and PSA+Annuity reform proposals entail less distortion on savings, something that comes as a consequence of a low level of payroll tax, the level of capital stock in both cases is higher than that of a $P A Y G$ system. Not surprisingly, the complete elimination of a PAYG system also induces a higher capital stock compared to that of $P A Y G$. Capital stock levels in $P S A$ and $P S A+A n n u i t y$ reforms are higher than in the elimination scenario because individuals 
cannot borrow against the funds accumulated in their PSA accounts, even if it might be optimal to do so for consumption smoothing purposes. Note that the capital stock levels of elimination and PSA \& PSA+Annuity reforms are quite close numerically. Moreover, as it is the case in Fuster et al. (2005), the PSA+Annuity reform generates the highest capital stock.

An immediate interpretation of this lies in the fact that, as in Fuster et al. (2005), under the $P S A+A n n u i t y$ scenario the funds of the deceased are invested in the capital market while under the $P S A$ scenario they are transferred to the estates, resulting in a higher capital stock in the former scenario. The complete elimination of social security scenario induces the highest welfare improvement followed by the $P S A+$ Annuity and $P S A$ reforms respectively. This happens because the elimination reform allows individuals to engage in consumption smoothing more efficiently than the other proposed reforms. Note that welfare improvements generated by all three reform proposals are very close in magnitude because the respective levels of capital stock do not differ much.

Table 2: CRRA Preferences

\begin{tabular}{llllllll}
\hline \hline & $\tau_{s}(\%)$ & $\kappa(\%)$ & $K$ & $Y$ & $C$ & $K / Y$ & $E U$ \\
PAYG & 3.6 & 0 & 100 & 100 & 100 & 2.529 & 100 \\
PSA & 0.9 & 2.7 & 113.631 & 104.035 & 101.508 & 2.763 & 103.280 \\
PSA+Annuity & 0.9 & 2.7 & 122.703 & 106.543 & 102.808 & 2.913 & 103.563 \\
Elimination & 0 & 0 & 114.331 & 104.237 & 101.499 & 2.774 & 104.108 \\
\hline
\end{tabular}

The large and growing literature on time inconsistency and self-control issues suggests that preference specifications capturing individuals' self-control problems might provide richer insights to the observed behavior of individuals (for example see Frederick et al. (2002)). Needless to say, both time inconsistent preferences à la Phelps \& Pollak (1968) and self-control preferences à la Gul \& Pesendorfer (2004) have been extensively used in an attempt to shed light to various macroeconomic problems, with issues pertaining to social security being among the most prominent ones.

More specifically, while Imrohoroglu et al. (2003) analyze the welfare implications of the elimination of a PAYG-type social security system in an economy populated by individuals with time inconsistent preferences, Kumru \& Thanopoulos (2008) analyze the same policy proposal in an economy populated by individuals with self control preferences. The latter study concludes that the welfare implications of the elimination of the PAYG system may vary drastically even if individuals' self control problems differ only to a small extent.

Although the elimination of a PAYG social security system is one policy option, transforming the system into a partially or fully-funded one could very well be alternative 
policies worth investigating. The types of PSA and PSA+Annuity policies we analyze in this paper are similar to the ones analyzed Storesletten et al. (1999) and Fuster et al. (2005) and those proposed in the reform recommendations made by the 1997 Advisory Council on Social Security ${ }^{15}$. In what follows, we proceed to examine the implications of the aforementioned reform proposals under the assumption that individuals have selfcontrol preferences. Before presenting our results for the benchmark case, we first explain the behavioral implications of the existence of temptation and then quantify the effects of temptation on economic aggregates.

Following DeJong \& Ripoll (2007), Kumru \& Thanopoulos (2008) calculated the quantity of steady-state consumption that would have to be given up by a self control individual in order to escape from temptation; Kumru \& Thanopoulos (2008) showed that individuals would be willing to forgo as much as $4.82 \%$ of their steady state consumption in order to eliminate temptation. This clearly demonstrates the welfare reducing effect that a self-control problem entails.

Next, we quantify steady-state levels of capital accumulation and consumption under the assumption that individuals have self-control preferences. By keeping the annual discount factor at its CRRA level, we first fix $\rho$ at 2 and vary $\lambda$ then we fix $\lambda$ at 0.00009 and vary $\rho$. Tables 3 and 4 display our results for both cases. The results are the same as those in Kumru \& Thanopoulos (2008). Table 3 demonstrates that an increase in the intensity of temptation distorts capital accumulation severely and causes a reduction in steady-state consumption. Similarly, Table 4 shows the effects of an increase in an individual's willingness to substitute current temptation consumption with future temptation consumption. Higher values of $\rho$ mean that individuals prefer more current temptation consumption. Not surprisingly, higher values of $\rho$ result in a reduction in the steady-state level of capital, which in turn causes a reduction in the steady-state level of consumption.

Table 3: $(\beta=0.978, \gamma=2, \rho=2)$

\begin{tabular}{lllllll}
\hline \hline$\lambda$ & $Y$ & $K$ & $C$ & $K / Y$ & $r$ & $w$ \\
\hline$C R R A$ & 1.188 & 2.892 & 0.960 & 2.434 & 0.081 & 1.044 \\
$\lambda=0.0004$ & 1.120 & 2.386 & 0.939 & 2.132 & 0.103 & 0.984 \\
$\lambda=0.001$ & 1.067 & 2.046 & 0.918 & 1.917 & 0.122 & 0.938 \\
\hline
\end{tabular}

In this section we present our results for an economy in which agents have self-control preferences and we compare the effects of the aforementioned three reform proposals on

\footnotetext{
${ }^{15}$ Please consult Fuster et al. (2005) for a detailed exposition of the reform proposals with regard to the US social security system.
} 
Table $4:(\beta=0.978, \lambda=0.00009)$

\begin{tabular}{lllllll}
\hline \hline$\lambda$ & $Y$ & $K$ & $C$ & $K / Y$ & $r$ & $w$ \\
\hline$C R R A$ & 1.188 & 2.892 & 0.960 & 2.434 & 0.081 & 1.044 \\
$\rho=2$ & 1.168 & 2.735 & 0.954 & 2.342 & 0.087 & 1.026 \\
$\rho=3$ & 1.075 & 2.091 & 0.922 & 1.946 & 0.119 & 0.944 \\
\hline
\end{tabular}

both economic aggregates and social welfare. Our model provides the opportunity to compare the effects of two opposite factors on savings (capital accumulation). While the existence/availability of PSAs causes an increase in savings, individuals with self-control preferences save less in order to escape from the huge self-control cost associated with resisting to temptation once the accumulated assets become available. We present our results in Table 5. The effects of the three reform proposals on economic aggregates and social welfare are slightly different from those we documented in Table 2 for an economy populated by individuals featuring CRRA preferences. In particular, the highest levels of capital stock and average expected utility are reached under the $P S A+$ Annuity reform scenario.

Table 5: Self-Control Preferences

\begin{tabular}{llllllll}
\hline \hline & $\tau_{s}(\%)$ & $\kappa(\%)$ & $K$ & $Y$ & $C$ & $K / Y$ & $E U$ \\
PAYG & 3.6 & 0 & 100 & 100 & 100 & 2.350 & 100 \\
PSA & 0.9 & 2.7 & 116.167 & 104.781 & 102.015 & 2.620 & 103.212 \\
PSA+Annuity & 0.9 & 2.7 & 128.049 & 107.970 & 103.993 & 2.795 & 104.324 \\
Elimination & 0 & 0 & 111.501 & 103.434 & 101.443 & 2.517 & 101.512 \\
\hline
\end{tabular}

For the sake of a more concise comparison, we created Table 6; this table presents the levels of capital stock and average expected utility under the three alternative reform proposals for both CRRA and self-control cases. Table 6 reveals that while the elimination reform scenario yields the highest welfare in the CRRA case, the PSA+Annuity reform yields the highest welfare in the self-control case. The intuition is the following: Individuals with self-control preferences are tempted to consume their entire wealth each period. Payroll taxes help those individuals to reduce their cost of exerting self-control in order to resist temptation. This additional benefit provided by a PAYG system creates welfare improvement.

Still, this additional benefit of a PAYG system is not large enough to exceed the benefits associated with eliminating the entire social security system. The PSA reforms provide the same additional benefit to working age individuals as the PAYG system. 
Although under CRRA preferences the elimination scenario results in the highest welfare gain, the welfare benefits of PSA+Annuity and PSA scenarios are higher under selfcontrol preferences. The reason why this obtains is simple: $P S A$ reforms not only provide the additional benefit of PAYG system but also come with higher retirement provisions.

Table 6: Comparison

\begin{tabular}{lllll}
\hline \hline & CRRA & \multicolumn{3}{c}{ Self-Control } \\
\hline & $K$ & $E U$ & $K$ & $E U$ \\
PAYG & 100 & 100 & 100 & 100 \\
PSA & 113.631 & 103.280 & 116.167 & 103.212 \\
PSA+Annuity & 122.703 & 103.563 & 128.049 & 104.324 \\
Elimination & 114.331 & 104.108 & 111.501 & 101.512 \\
\hline
\end{tabular}

Finally we check the case where individuals face an extremely severe self-control problem. For this purpose we set the risk-aversion parameter of the momentary utility function, $\gamma$, equal to 2 and we set the temptation function parameters $\rho$ and $\lambda$ equal to 2 and 0.00065 respectively. We choose $\beta=1.0117$ in order to converge to the long-term capital-output ratio of the US economy when a PAYG system is in use. Table 7 below presents the results.

Table 7: Severe Temptation

\begin{tabular}{llllllll}
\hline \hline & $\tau_{s}(\%)$ & $\kappa(\%)$ & $K$ & $Y$ & $C$ & $K / Y$ & $E U$ \\
PAYG & 3.6 & 0 & 100 & 100 & 100 & 2.350 & 100 \\
PSA & 0.9 & 2.70 & 117.038 & 104.991 & 102.088 & 2.620 & 101.970 \\
PSA+Annuity & 0.9 & 2.70 & 128.584 & 108.101 & 103.970 & 2.795 & 103.958 \\
Elimination & 0 & 0 & 110.475 & 103.130 & 101.320 & 2.517 & 98.443 \\
\hline
\end{tabular}

As it can be seen in Table 7, in contrast to our previous results, the current $P A Y G$ system dominates the elimination reform by generating higher welfare. Since $P S A$ and $P S A+A n n u i t y$ reforms provide the same additional benefit as $P A Y G$, it comes as no surprise that in the case of severe temptation they end-up performing better than the elimination scenario.

Because of higher retirement benefits, in this environment both $P S A$ and $P S A+$ Annuity reforms outperform the $P A Y G$ scenario with regards to welfare. A higher value of the time preference parameter, $\beta$, might contribute in delivering the above results. Nevertheless, these results are important in that they blatantly manifest how sensitive are 
the welfare consequences of various reform proposals to little deviations from the CRRA case.

In summary, we show that if an economy is populated by individuals with self-control problems, the gain from the two reform proposals is larger than what we observed in the CRRA case. More interestingly the elimination reform proposal even decreases welfare in comparison to the PAYG system when individuals have severe temptation problem.

\section{Conclusions}

Population aging due to low birth and morbidity rates and the resulting expansion of social security benefits have prompted lively debates around the long-term viability of unfunded social security. ${ }^{16}$ Several reform proposals are being discussed for the US Economy and other industrialized countries, all of which converge to a common resultant: social security must be reformed in the direction of a funded rather than an unfunded system.

In this paper we examine departures from a Pay-As-You-Go social security system towards a system consisting of two parts: A "defined benefits" component and a "defined contributions" one. This is implemented by means of annexing a(n) (individually managed) Personal Security Account to a universal (PAYG-based) pension system.

We quantitatively assess the attractiveness (i.e., the welfare enhancing potential) of such a funded scheme in an economy populated by agents that face self control issues. To this purpose, we use two different benchmarks: a economy featuring PAYG social security populated by self control agents (Kumru \& Thanopoulos (2008)) and an economy featuring funded (as in this paper) social security but populated by CRRA agents. Furthermore, we refine our analysis by investigating the relative appeal of two distinct scenarios: PSAs without annuitization and PSAs with mandatory annuitization.

Our analysis suggests that the availability of PSAs increases savings. This is principally true for CRRA agents. However, it is very ambiguous whether self-control agents will be better off with a genuine PAYG system, or with a funded system of the analyzed hybrid structure that prescribes mandatory annuitization, as it eventually depends on the intensity of the self-control problem.

Our results in this paper highlight the important role that self control preferences play, especially with regards to the kind of reform that could generate the highest welfare. While when the analysis is restricted to CRRA preferences our findings initially confirm those in other studies (e.g.,Fuster et al. (2005)), i.e., we also find that the complete elimination of any social security is the policy that maximizes welfare, when self-control

\footnotetext{
${ }^{16}$ See US Social Security Administration (2008)
} 
preferences are introduced instead, we come across a drastic alteration of our results: the elimination of social security becomes the least desirable policy reform from a welfare maximization standpoint, i.e., $P S A$ and $P S A+A n n u i t y$ reforms give rise to larger welfare improvements under self-control preferences.

In conclusion, our research indicates that the incontestable advantage of the elimination scenario under CRRA preferences rapidly vanishes as self control is introduced and becomes progressively more severe. Our additional example confirms this finding: in the case of severe temptation the CRRA pecking order is completely reversed, and the elimination of social security becomes the least desirable policy.

\section{References}

Auerbach, A. J., \& Kotlikoff, L. J. 1987. Dynamic Fiscal Policy. New York, NY, USA: Cambridge University Press.

DeJong, D. N., \& Ripoll, M. 2007. Do self-control preferences help explain the puzzling behavior of asset prices? Journal of Monetary Economics, 54, 1035-1050.

DeNardi, M., Imrohoroglu, S., \& Sargent, T. 1999. Projected U.S. demographics and social security. Review of Economic Dynamics, 2, 575-615.

Diamond, P. A. 1965. National debt in a neoclassical growth model. American Economic Review, 55, 1126-1150.

Diamond, P. A., \& Orszag, P. R. 2005. Saving social security. Journal of Economic Perspectives, 19, 11-32.

Diamond, P. A., Brown, J., \& Thomas, D. 2005. Annuities and individual welfare. American Economic Review, 95, 1573-1590.

Fehr, H., \& Kindermann, F. 2009. Pension Funding and Individual Accounts in Economies with Life-cyclers and Myopes. Working Paper.

Fehr, H., Habermann, C., \& Kindermann, F. 2008. Social Security with Rational and Hyperbolic Consumers. Review of Economic Dynamics, 11(4), 884-903.

Feldstein, M., \& Liebman, J. B. 2002. Social Security. In: Auerbach, A. J., \& Feldstein, M. (eds), Handbook of Public Economics. New York, NY, USA: Elsevier Science B. V.

Frederick, S., Loewenstein, G., \& O’Donoughe, T. 2002. Time discounting and time preference: A critical review. Journal of Economic Literature, 40, 351-401. 
Fuster, L., Imrohoroglu, A., \& Imrohoroglu, S. 2003. A welfare analysis of social security in a dynastic framework. International Economic Review, 44, 1247-1274.

Fuster, L., Imrohoroglu, A., \& Imrohoroglu, S. 2005. Personal security accounts and mandatory annuitization in a dynastic framework. Working Paper, 119-158.

Gul, F., \& Pesendorfer, W. 2004. Self control and theory of consumption. Econometrica, 72, 119-158.

Hansen, G. 1993. The cyclical and secular behavior of the labor input: comparing efficiency units and hours worked. Journal of Applied Econometrics, 8, 71-80.

Hugget, M., \& Ventura, G. 1999. On the distributional effects of social security reform. Review of Economic Dynamics, 2, 498-531.

Imrohoroglu, A., Imrohoroglu, S., \& Joines, D. H. 1995. A life cycle analysis of social security. Economic Theory, 6, 83-114.

Imrohoroglu, A., Imrohoroglu, S., \& Joines, D. H. 2003. Time inconsistent preferences and social security. Quarterly Journal of Economics, 118, 745-784.

Kumru, C. S., \& Thanopoulos, A. C. 2008. Social security and self control preferences. Journal of Economic Dynamics and Control, 32, 757-778.

Phelps, E. S., \& Pollak, R. A. 1968. On second-best national savings and gameequilibrium growth. Review of Economic Studies, 35, 185-199.

Rojas, J. A., \& Urrutia, C. 2008. Social security reform with uninsurable income risk and endogenous borrowing constraints. Review of Economic Dynamics, 11, 83-103.

Storesletten, K., Telmer, C. I., \& Yaron, A. 1999. The risk sharing implications of alternative social security arrangements. Carnegie-Rochester Conference Series on Public Policy, 50, 213-259.

U.S. Census Bureau. 2006. Mini historical statistics: population. $<$ http://www.census.gov $>$.

US Department of Labor. 2006. Labor force statistics from current poplulation survey. $<$ http://www.bls.gov $>$.

US Social Security Administration. 2008. Fast facts and figures about social security. $<$ http://www.ssa.gov $>$. 


\section{CESifo Working Paper Series}

for full list see www.cesifo-group.org/wp

(address: Poschingerstr. 5, 81679 Munich, Germany, office@cesifo.de)

2717 Ben J. Heijdra and Jochen O. Mierau, Annuity Market Imperfection, Retirement and Economic Growth, July 2009

2718 Kai Carstensen, Oliver Hülsewig and Timo Wollmershäuser, Price Dispersion in the Euro Area: The Case of a Symmetric Oil Price Shock, July 2009

2719 Katri Kosonen and Gaëtan Nicodème, The Role of Fiscal Instruments in Environmental Policy, July 2009

2720 Guglielmo Maria Caporale, Luca Onorante and Paolo Paesani, Inflation and Inflation Uncertainty in the Euro Area, July 2009

2721 Thushyanthan Baskaran and Lars P. Feld, Fiscal Decentralization and Economic Growth in OECD Countries: Is there a Relationship?, July 2009

2722 Nadia Fiorino and Roberto Ricciuti, Interest Groups and Government Spending in Italy, 1876-1913, July 2009

2723 Andreas Wagener, Tax Competition, Relative Performance and Policy Imitation, July 2009

2724 Hans Fehr and Fabian Kindermann, Pension Funding and Individual Accounts in Economies with Life-cyclers and Myopes, July 2009

2725 Ernesto Reuben and Arno Riedl, Enforcement of Contribution Norms in Public Good Games with Heterogeneous Populations, July 2009

2726 Kurt Schmidheiny and Marius Brülhart, On the Equivalence of Location Choice Models: Conditional Logit, Nested Logit and Poisson, July 2009

2727 Bruno S. Frey, A Multiplicity of Approaches to Institutional Analysis. Applications to the Government and the Arts, July 2009

2728 Giovanni Villani, A Strategic R\&D Investment with Flexible Development Time in Real Option Game Analysis, July 2009

2729 Luca Di Corato and Michele Moretto, Investing in Biogas: Timing, Technological Choice and the Value of Flexibility from Inputs Mix, July 2009

2730 Gilad D. Aharonovitz, Nathan Skuza and Faysal Fahs, Can Integrity Replace Institutions? Theory and Evidence, July 2009

2731 Michele Moretto and Sergio Vergalli, Managing Migration through Conflicting Policies: an Option-theory Perspective, July 2009 
2732 Volker Nitsch, Fly or Cry: Is Airport Noise Costly?, July 2009

2733 Francesco Cinnirella and Joachim Winter, Size Matters! Body Height and Labor Market Discrimination: A Cross-European Analysis, July 2009

2734 Samuel Bowles and Sandra Polanía Reyes, Economic Incentives and Social Preferences: A Preference-based Lucas Critique of Public Policy, July 2009

2735 Gary Burtless, Lessons of the Financial Crisis for the Design of National Pension Systems, July 2009

2736 Helmuth Cremer, Firouz Gahvari and Pierre Pestieau, Fertility, Human Capital Accumulation, and the Pension System, July 2009

2737 Hans Jarle Kind and Frank Stähler, Market Shares in Two-Sided Media Industries, July 2009

2738 Pamela Campa, Alessandra Casarico and Paola Profeta, Gender Culture and Gender Gap in Employment, August 2009

2739 Sebastian Gechert, Supplementary Private Health Insurance in Selected Countries: Lessons for EU Governments?, August 2009

2740 Leif Danziger, Endogenous Monopsony and the Perverse Effect of the Minimum Wage in Small Firms, August 2009

2741 Yan Dong and John Whalley, A Third Benefit of Joint Non-OPEC Carbon Taxes: Transferring OPEC Monopoly Rent, August 2009

2742 Valentina Bosetti, Carlo Carraro and Massimo Tavoni, Climate Change Mitigation Strategies in Fast-Growing Countries: The Benefits of Early Action, August 2009

2743 Christina Felfe, The Willingness to Pay for Job Amenities: Evidence from Mothers' Return to Work, August 2009

2744 Jörg Franke, Christian Kanzow, Wolfgang Leininger and Alexandra Väth, Effort Maximization in Asymmetric N-Person Contest Games, August 2009

2745 Bruno S. Frey and Paolo Pamini, Making World Heritage Truly Global: The Culture Certificate Scheme, August 2009

2746 Frank N. Caliendo, Is Social Security behind the Collapse of Personal Saving?, August 2009

2747 Caterina Liesegang and Marco Runkel, Corporate Income Taxation of Multinationals and Fiscal Equalization, August 2009

2748 Chrysovalantou Milliou and Apostolis Pavlou, Upstream Horizontal Mergers and Efficiency Gains, August 2009 
2749 Rüdiger Pethig and Christian Wittlich, Interaction of Carbon Reduction and Green Energy Promotion in a Small Fossil-Fuel Importing Economy, August 2009

2750 Kai Carstensen, Oliver Hülsewig and Timo Wollmershäuser, Monetary Policy Transmission and House Prices: European Cross-country Evidence, August 2009

2751 Olaf Posch, Explaining Output Volatility: The Case of Taxation, August 2009

2752 Beatrice Scheubel, Daniel Schunk and Joachim Winter, Don't Raise the Retirement Age! An Experiment on Opposition to Pension Reforms and East-West Differences in Germany, August 2009

2753 Daniel G. Arce, Dan Kovenock and Brian Roberson, Suicide Terrorism and the Weakest Link, August 2009

2754 Mario Larch and Wolfgang Lechthaler, Comparative Advantage and Skill-Specific Unemployment, August 2009

2755 Horst Raff and Nicolas Schmitt, Buyer Power in International Markets, August 2009

2756 Seppo Kari, Hanna Karikallio and Jukka Pirttilä, The Impact of Dividend Taxation on Dividends and Investment: New Evidence Based on a Natural Experiment, August 2009

2757 Mirco Tonin and Michael Vlassopoulos, Disentangling the Sources of Pro-social Behavior in the Workplace: A Field Experiment, August 2009

2758 Nicole Grunewald and Inmaculada Martínez-Zarzoso, Driving Factors of Carbon Dioxide Emissions and the Impact from Kyoto Protocol, August 2009

2759 Yu-Fu Chen and Michael Funke, Booms, Recessions and Financial Turmoil: A Fresh Look at Investment Decisions under Cyclical Uncertainty, August 2009

2760 Jan-Egbert Sturm and Jakob de Haan, Does Central Bank Communication really Lead to better Forecasts of Policy Decisions? New Evidence Based on a Taylor Rule Model for the ECB, August 2009

2761 Larry Karp, Sacrifice, Discounting and Climate Policy: Five Questions, August 2009

2762 Marianna Belloc and Samuel Bowles, International Trade, Factor Mobility and the Persistence of Cultural-Institutional Diversity, August 2009

2763 Charles Noussair and Fangfang Tan, Voting on Punishment Systems within a Heterogeneous Group, August 2009

2764 Birgit Bednar-Friedl and Karl Farmer, Internationally Coordinated Emission Permit Policies: An Option for Withdrawers from the Kyoto Protocol?, August 2009

2765 Pierre M. Picard and David E. Wildasin, Labor Market Pooling, Outsourcing and Labor Contracts, August 2009 
2766 Stefan Voigt and Lorenz Blume, The Economic Effects of Federalism and Decentralization - A Cross-Country Assessment, August 2009

2767 David S. Jacks, Christopher M. Meissner and Dennis Novy, Trade Booms, Trade Busts, and Trade Costs, August 2009

2768 Mario Jametti and Thomas von Ungern-Sternberg, Hurricane Insurance in Florida, August 2009

2769 Alessandro Balestrino, Kind of Black: The Musicians' Labour Market in Italy, August 2009

2770 Yosr Abid Fourati and Cathal O’Donoghue, Eliciting Individual Preferences for Pension Reform, August 2009

2771 Christian Breuer and Chang Woon Nam, VAT on Intra-Community Trade and Bilateral Micro Revenue Clearing in the EU, August 2009

2772 Choudhry Tanveer Shehzad, Jakob De Haan and Bert Scholtens, Growth and Earnings Persistence in Banking Firms: A Dynamic Panel Investigation, August 2009

2773 Erdal Yalcin, Uncertain Productivity Growth and the Choice between FDI and Export, August 2009

2774 Klaus Abberger, Wolfgang Nierhaus and Shynar Shaikh, Findings of the Signal Approach for Financial Monitoring in Kazakhstan, September 2009

2775 Sascha O. Becker, Francesco Cinnirella and Ludger Woessmann, The Trade-off between Fertility and Education: Evidence from before the Demographic Transition, September 2009

2776 Thomas Aronsson and Erkki Koskela, Optimal Income Taxation, Outsourcing and Policy Cooperation in a Dynamic Economy, September 2009

2777 Joel Slemrod, Old George Orwell Got it Backward: Some Thoughts on Behavioral Tax Economics, September 2009

2778 Cagri Seda Kumru and Athanasios C. Thanopoulos, Social Security Reform and Temptation, September 2009 